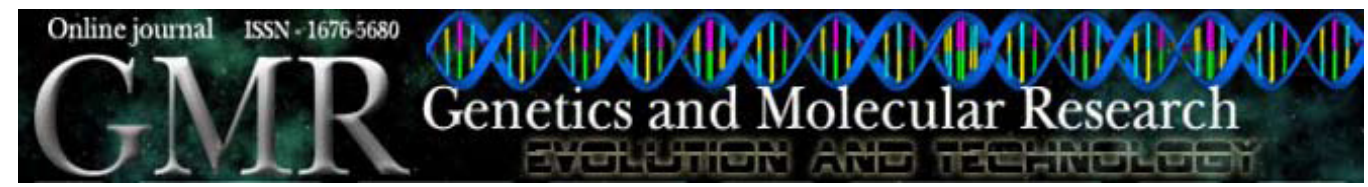

\title{
Clinical outcome in chronic myeloid leukemia after allogeneic hematopoietic stem cell transplantation: the experience of the Bone Marrow Transplantation Unit of FUNFARME/ BRAZIL using FISH
}

C.B. Vendrame-Goloni' ${ }^{1}$, A.B. Carvalho-Salles ${ }^{2}$, M.A. Ruiz ${ }^{3}$, O. Ricci Júnior ${ }^{2}$, M. Varella-Garcia ${ }^{4}$ and A.C. Fett-Conte ${ }^{5}$

${ }^{1}$ Departamento de Biologia, Instituto de Biociências Letras e Ciências Exatas, Universidade Estadual Paulista, São José do Rio Preto, SP, Brasil

${ }^{2}$ Hemocentro, Fundação Faculdade Regional de Medicina de São José do Rio Preto, São José do Rio Preto, SP, Brasil

${ }^{3}$ Unidade de Transplante de Medula, Fundação Faculdade Regional de Medicina de São José do Rio Preto, São José do Rio Preto, SP, Brasil

${ }^{4}$ University of Colorado Comprehensive Cancer Center, Denver, CO, USA

${ }^{5}$ Departamento de Biologia Molecular, Faculdade de Medicina de São José do Rio Preto, São José do Rio Preto, SP, Brasil

Corresponding author: C.B. Vendrame-Goloni

E-mail: cristina.benitez@ig.com.br

Genet. Mol. Res. 7 (2): 417-423 (2008)

Received February 11, 2008

Accepted March 4, 2008

Published May 7, 2008

ABSTRACT. Investigation of the efficacy of allogeneic hematopoietic
stem cell transplantation (allo-HSCT) in chronic myeloid leukemia patients
is essential to predict prognosis and survival. In 20 patients treated at the
Bone Marrow Transplantation Unit of São José do Rio Preto (São Paulo,
Brazil), we used fluorescence in situ hybridization (FISH) to investigate
the frequency of cells with BCR/ABL rearrangement at diagnosis and at 
distinct intervals after allo-HSCT until complete cytogenetic remission (CCR). We investigated the disease-free survival, overall survival in 3 years and transplant-related mortality rates, too. Bone marrow samples were collected at 1, 2, 3, 4, 6, 12, and 24 months after transplantation and additional intervals as necessary. Success rate of the FISH analyses was $100 \%$. CCR was achieved in $75 \%$ of the patients, within on average of 3.9 months; $45 \%$ patients showed CCR within 60 days after HSCT. After 3 years of the allo-HSCT, overall survival rate was $60 \%$, disease-free survival was $50 \%$ and the transplant-related mortality rate was $40 \%$. The study demonstrated that the BCR-ABL FISH assay is useful for followup of chronic myeloid leukemia patients after HSCT and that the clinical outcome parameters in our patient cohort were similar to those described for other bone marrow transplantation units.

Key words: Chronic myelogenous leukemia; Disease-free survival; BCR-ABL fusion; Stem cell transplantation; Cytogenetic remission; Fluorescence in situ hybridization

\section{INTRODUCTION}

Chronic myeloid leukemia (CML) is a malignant disorder of an early hematopoietic progenitor cell that is genetically characterized by the presence of a BCR/ABL fusion (Haigh and Cuthbert, 2005). In the majority of cases, the fusion arises from a reciprocal translocation between the $A B L$ locus on $9 \mathrm{q} 34$ and the $B C R$ locus on $22 \mathrm{q} 11.2$, resulting in the classical Philadelphia $(\mathrm{Ph})$ chromosome. CML is clinically characterized by an initial chronic phase followed by accelerated and blast crisis phases, the latter being frequently resistant to treatment (Aoun et al., 2004).

Allogeneic hematopoietic stem cell transplantation (allo-HSCT) is the modality of treatment that provides a potential cure for CML, but clinical relapse post-HSCT is an ongoing problem (Soydan et al., 2005). Relapse rates after allo-HSCT vary from 20 to $50 \%$, depending on T-cell depletion of the graft (Posthuma et al., 2004); rates are lower in patients allografted in the chronic phase with unmanipulated cells than when donor marrow cells are T-cell depleted (Olavarria et al., 2003).

The aim of allo-HSCT is to replace autologous hematopoiesis with stem cells harvested from the donor. However, autologous (host) cells may be detected in peripheral blood or bone marrow of some patients after the procedure. The clinical significance of this phenomenon, called mixed chimerism or persistence of residual (host) hematopoiesis, remains controversial. Increased mixed chimerism may be associated with a high risk of relapse or rejection, and a decrease in the number of host cells may indicate a low risk of recurrence. The consequence of the stable presence of a low-level autologous signal is still unclear and results in doubt about the best choice of therapeutic approaches for the patient (Wickenhauser et al., 2002; Turkiewicz et al., 2003).

The major aim of post-transplant monitoring is to detect negative events early, such as disease relapse, graft rejection and graft-versus-host disease, and to start the appropriate therapy. In this context, molecular cytogenetics is an important laboratory tool to monitor post-HSCT outcomes through the detection of positive Ph clones. The fluorescence in situ hybridization (FISH) assay is a powerful technique to clarify cytogenetic rearrangements (Vendrame-Goloni 
et al., 2003; Fett-Conte et al., 2007). Especially when using a dual-color-dual-fusion probe, FISH can be used to monitor CML patients post-allo-HSCT regularly (Khan et al., 2004). Cytogenetic remission is critical to define engraftment and relapse and is a prerequisite in both myeloablative and non-myeloablative HSCT, in order to assess the graft status and decide future therapeutic strategies (Au et al., 2003; Khan et al., 2004). Therapeutic approaches for patients in relapse after allografting include $\alpha$-interferon, chemotherapy, a second HSCT, and immunomodulation with donor lymphocyte infusions (Olavarria et al., 2003), as well as tyrosine kinase inhibitors (imatinib and dasatinib, for example) which block progenitor cell proliferation (Fausel, 2006).

This study used FISH to investigate the time to complete cytogenetic remission (CCR) after allo-HSCT in CML patients treated in the FUNFARME Bone Marrow Transplantation Unit from 2002 until 2004. Other clinical outcome parameters investigated were the diseasefree survival (DFS), overall survival (OS) and transplant-related mortality (TRM) rates.

\section{PATIENTS, MATERIAL AND METHODS}

We studied 20 CML patients, diagnosed according to the World Health Organization criteria. All patients showed a BCR/ABL rearrangement at diagnosis detected by FISH and/ or GTG-banding karyotyping in bone marrow cells. The mean frequency of cells carrying the $\mathrm{BCR} / \mathrm{ABL}$ rearrangement at diagnosis was $84 \%$, varying from 56 to $100 \%$. Bone marrow samples were collected at 1, 2, 3, 4, 6, 12, and 24 months after allogeneic myeloablative HSCT and at other additional intervals according to the medical indication of each case. All patients were previously submitted to the BUCY (busulfan and cyclophosphamide) protocol as conditioning regimen (Thomas and Clift, 1998; Clift et al., 1999).

Bone marrow cells were added to a 24-h non-stimulated culture in RPMI 1640 medium with $20 \%$ fetal bovine serum. FISH assays were performed with the dual-color, dual-fusion DNA probe for BCR/ABL (LSI/BCR labeled in SpectrumGreen and LSI/ABL labeled in SpectrumOrange, Vysis/Abbott Molecular). The protocols for hybridization followed those described by Estécio et al. (2002) and manufacturer instructions. At least 800 interphase cells were analyzed per patient in each examination, and data were described according to the International System for Human Cytogenetic Nomenclature (ISCN, 1995). Lymphocytes from healthy individuals were used as control in each assay, in which no $B C R / A B L$-positive cells were identified.

$\mathrm{CCR}$ was defined as the absence of $\mathrm{BCR} / \mathrm{ABL}$ rearrangements evidenced by FISH. DFS was considered as the length of time after HSCT during which no disease was found (no hematological and/or cytogenetic abnormalities). Patients who died were not considered when determining DFS, even if the cause of death was an infection, because the follow-up was interrupted. OS was defined as the percentage of patients who survived for a period of 3 years, and the mean values were calculated using the Kaplan-Meier method.

\section{RESULTS}

The ages, time from HSCT to CCR, DFS rate and events observed post-HSCT for each patient are shown in Table 1. The mean of cytogenetic follow-up was 11.8 months. Among the 20 patients, 15 (75\%) achieved CCR between one and 19 months after the procedure, with a mean time of 3.9 months. Nine patients $(45 \%)$ achieved CCR up to 60 days after the HSCT, a time considered indicative of good prognosis. One patient (case 6) achieved CCR only after 19 
months, although the frequency of $\mathrm{BCR} / \mathrm{ABL}$ rearrangement was very low $(<0.5 \%)$ in the last 14 months before CCR was reached. There was no association between the frequency of cells with $\mathrm{BCR} / \mathrm{ABL}$ fusion at the diagnosis of $\mathrm{CML}$ and the time to achieve CCR.

\begin{tabular}{|c|c|c|c|c|}
\hline Case & Age (years) & CCR (months) & DFS (months) & Post-transplant events \\
\hline 1 & 38 & 0 & 0 & death $\rightarrow$ (stroke $)$ \\
\hline 2 & 13 & 4 & 31 & $\mathrm{~N}$ \\
\hline 3 & 36 & 4 & 31 & death (I) \\
\hline 4 & 29 & 2 & 29 & $\mathrm{~N}$ \\
\hline 5 & 20 & 2 & 5 & relapse $\rightarrow$ 2nd HSCT $\rightarrow$ death (I) \\
\hline 6 & 34 & 19 & 25 & $\mathrm{~N}$ \\
\hline 7 & 46 & 1 & 28 & $\mathrm{~N}$ \\
\hline 8 & 25 & 1 & 27 & $\mathrm{~N}$ \\
\hline 9 & 39 & 2 & 3 & death (I) \\
\hline 10 & 29 & 1 & 12 & $\mathrm{~N}$ \\
\hline 11 & 37 & 2 & 23 & $\mathrm{~N}$ \\
\hline 12 & 40 & 2 & 10 & relapse $\rightarrow$ death (I) \\
\hline 13 & 37 & 0 & 0 & relapse $\rightarrow$ imatinib $\rightarrow$ bone marrow aplasia $\rightarrow$ death (I) \\
\hline 14 & 16 & 6 & 11 & $\mathrm{~N}$ \\
\hline 15 & 27 & 3 & 10 & $\mathrm{~N}$ \\
\hline 16 & 34 & 0 & 0 & $\mathrm{~N}$ \\
\hline 17 & 42 & 1 & 11 & $\mathrm{~N}$ \\
\hline 18 & 44 & 9 & 12 & $\mathrm{~N}$ \\
\hline 19 & 43 & 0 & 0 & $\mathrm{~N}$ \\
\hline 20 & 37 & 0 & 0 & relapse $\rightarrow$ death (I) \\
\hline
\end{tabular}

The median DFS was 9.8 months and the 3-year DFS rate was $50 \%$. The OS rate was $60 \%$ in 3 years. There was no association between period of time to achieve CCR, DFS and OS time $(\mathrm{P}=0.001)$.

In 3 years, the TRM rate was $40 \%$ and the relapse rate was $20 \%$. Five patients $(25 \%)$ did not achieve CCR. Three of them died, one because the disease affected the central nervous system and two due to infections (one after introduction of imatinib mesylate). The other two patients did not present post-HSCT events. Five patients who had achieved CCR died from infections between one and four months after the allo-HSCT.

\section{DISCUSSION}

The success of allo-HSCT depends to a great extent on the cytogenetic follow-up of the patient, which influences the therapeutic management. Patients who show the BCR/ABL rearrangement in progressively higher frequencies after the procedure are at greater risk of relapse and are candidates for additional and more aggressive therapies. However, patients with stable or decreasing frequencies seem to have immunological mechanisms suppressing the malignant clone, or perhaps this clone may lose its proliferative capacity resulting in a lower risk of relapse (Gopcsa et al., 2003).

The FISH technique is especially valuable for investigating patients after HSCT, because it is more sensitive and can be performed faster than classical cytogenetics. The dual- 
color interphase FISH has higher sensitivity in detecting $B C R / A B L$ fusion gene, but interphase-dual-color and dual-fusion FISH is a more reliable, sensitive and practicable test for monitoring minimal residual disease and CCR after transplantation (Liu Q et al., 2005; Qian et al., 2006). This was the test used here. Dynamic detection of $B C R / A B L$ fusion gene level by FISH may predict disease changes and guide individual therapy (Qian et al., 2006). Other techniques such as reverse transcriptase-polymerase chain reaction, real time quantitative polymerase chain reaction and microarray are also sensitive (Yokota et al., 2002).

Most of the patients (75\%) treated in the FUNFARME BMT unit during the selected period achieved CCR, $45 \%$ of whom within the first two months after HSCT. These results are similar to reported CCR rates in developing countries such as China and Greece, which varied from 56 to 95.9\% (Vinogradova et al., 2002; Liu et al., 2004a,b; Liu DH et al., 2005; Qin et al., 2006).

Patients with CCR within two months have a better prognosis (Imparato et al., 1999; Kebriaei et al., 2004). However, four patients in our study who had good prognosis died: two of them relapsed, were submitted to another therapeutic modality (second HSCT and therapy with imatinib mesylate) and died due to infections; two others did not relapse but had fatal infections. In other countries, the CCR rates are similar. For example, Vinogradova et al. (2002) found $56 \%$ in Russian patients.

In Brazil, the data on CCR post-allo-HSCT are rare. The only data that we found were of Chauffaille et al. (2001). They observed a 83\% CCR rate one year after HSCT using FISH, but they used a double-color and single-fusion probe. Although all of these 12 patients studied showed the fusion, the cut off level was established as $10 \%$.

Patients in relapse after allo-HSCT have few therapeutic options. A second allo-HSCT may be a good therapeutic alternative for selected patients with relapsed leukemia after the first HSCT. Yang et al. (2004) related a relapse rate at 2 years after the second allo-HSCT of $30 \%$. The use of imatinib may also have a significant effect (Fujisawa et al., 2003; Gopcsa et al., 2003). Soydan et al. (2005) concluded that imatinib treatment for molecular relapse after HSCT has an acceptable adverse event profile and provides a molecular remission rate of over $60 \%$, but the response is short and $25 \%$ of the patients relapse again soon after drug cessation.

We found an OS rate of $60 \%$ in 3 years. It was not too good but did not differ greatly from other reported findings. In the USA, Simon et al. (2006) found a rate of $86 \%$ in 3 years.

The TRM rates described in the literature for a period of approximately 2 years after HSCT are variable. In Chinese patients, the mortality rate reported by Liu et al. (2004b) was $16.7 \%$. The rate experienced by Liubimova et al. (2004) was $14 \%$. De Souza et al. (2005) reported a rate of $45 \%$ and Valcarcel et al. (2005) published a rate of $30 \%$.

The TRM rate in this study was $40 \%$. In the majority of these cases $(87.5 \%)$, death occurred due to infections unrelated to relapse of disease in $43 \%$ of the patients, and Burroughs and Storb (2005) described a mortality rate unrelated to relapse in 15 to $55 \%$. Infections are complications considered relatively common after HSCT and are described in 38.6 to $59.6 \%$ of patients (Petzer and Gunsilius, 2003; Liubimova et al., 2004; Yang et al., 2004; Burroughs and Storb, 2005; De Souza et al., 2005; Valcarcel et al., 2005; Simon et al., 2006).

\section{CONCLUSION}

The dual-color, dual-fusion BCR/ABL FISH assay is useful in identifying cytogenetic remission after allogeneic HSCT in CML. The results of cytogenetic remission, disease-free 
survival rate and rate of transplant-related mortality in our study are in agreement with those published by other authors from different HSCT units.

\section{ACKNOWLEDGMENTS}

The authors wish to thank David A. Hewitt for the English correction of this manuscript. Research supported by grants from the Faculdade de Medicina de São José do Rio Preto (BAP/FAMERP) and Conselho Nacional de Desenvolvimento Científico e Tecnológico (CNPq) - Grant numbers: 3317/2004 and 141553/2004-9.

\section{REFERENCES}

Aoun P, Wiggins M, Pickering D, Foran J, et al. (2004). Interphase fluorescence in situ hybridization studies for the detection of $9 \mathrm{q} 34$ deletions in chronic myelogenous leukemia: a practical approach to clinical diagnosis. Cancer Genet. Cytogenet. 154: 138-143.

$\mathrm{Au}$ WY, Ma SK and Kwong YL (2003). The occurrence of Philadelphia chromosome (Ph) negative leukemia after hematopoietic stem cell transplantation for $\mathrm{Ph}$ positive chronic myeloid leukemia: implications for disease monitoring and treatment. Leuk. Lymphoma 44: 1121-1129.

Burroughs L and Storb R (2005). Low-intensity allogeneic hematopoietic stem cell transplantation for myeloid malignancies: separating graft-versus-leukemia effects from graft-versus-host disease. Curr. Opin. Hematol. 12: 45-54.

Chauffaille MLLF, Oliveira J, Romero M and Kerbauy J (2001). Fluorescent in situ hibridization (FISH) for BCR/ABL in chronic myeloid leukemia after bone marrow transplantation. SP Med. J. 119: 16-18.

Clift RA, Radich J, Appelbaum FR, Martin P, et al. (1999). Long-term follow-up of a randomized study comparing cyclophosphamide and total body irradiation with busulfan and cyclophosphamide for patients receiving allogenic marrow transplants during chronic phase of chronic myeloid leukemia. Blood 94: 3960-3962.

De Souza CA, Vigorito AC, Ruiz MA, Nucci M, et al. (2005). Validation of the EBMT risk score in chronic myeloid leukemia in Brazil and allogeneic transplant outcome. Haematologica 90: 232-237.

Estecio M, Fett-Conte AC, Varella-Garcia M, Fridman C, et al. (2002). Molecular and cytogenetic analyses on Brazilian youths with pervasive developmental disorders. J. Autism Dev. Disord. 32: 35-41.

Fausel CA (2006). Novel treatment strategies for chronic myeloid leukemia. Am. J. Health Syst. Pharm. 63: S15-S20.

Fett-Conte AC, Estrela RV, Vendrame-Goloni CB, Carvalho-Salles AB, et al. (2007). Atypical chromosome abnormalities in acute myeloid leukemia type M4. Genet. Mol. Biol. 30: 6-9.

Fujisawa S, Yano K and Kobayashi M (2003). A case of chronic myelogenous leukemia responding to imatinib mesilate (Glivec) after relapse of blastic crisis following allogeneic bone marrow transplantation. Gan To Kagaku Ryoho 30: 427-430.

Gopcsa L, Barta A, Bányai A, Dolgos J, et al. (2003). Salvage chemotherapy with donor lymphocyte infusion and STI 571 in a patient relapsing with B-lymphoblastic phase chronic myeloid leukemia after allogeneic bone marrow transplantation. Pathol. Oncol. Res. 9: 131-133.

Haigh S and Cuthbert G (2005). Fluorescence in situ hybridization characterization of different cryptic BCR-ABL rearrangements in chronic myeloid leukemia. Cancer Genet. Cytogenet. 156: 188-189.

Imparato FP, Menezes CL, Anelli A, Oliveira RM, et al. (1999). Co-evolução da terapêutica e do diagnóstico molecular da leucemia mielóide crônica. Acta Oncol. Bras. 19: 259-266.

ISCN (1995). An international system for human cytogenetics nomenclature. Karger S, Basel.

Kebriaei P, Winter JN, Laport GG, Le Beau MM, et al. (2004). Multiple unrelated clonal abnormalities in host bone marrow cells after allogeneic stem cell transplantation. Leuk. Res. 28: 537-540.

Khan F, Agarwal A and Agrawal S (2004). Significance of chimerism in hematopoietic stem cell transplantation: new variations on an old theme. Bone Marrow Transplant. 34: 1-12.

Liu DH, Huang XJ, Guo NL, Xu LP, et al. (2005). Analysis of pathogenesis of pneumonia post allogeneic hematopoietic stem cell transplantation. Beijing Da Хие Хие Bao 37: 130-133.

Liu QF, Sun J, Zhang Y, Liu XL, et al. (2004a). Hematopoietic stem cell transplantation for patients with chronic myelogenous leukemia. Ai Zheng 23: 426-429.

Liu QF, Fan ZP, Sun J, Zhang Y, et al. (2004b). Therapeutic efficacy of hematopoietic stem cell transplantation in patients with chronic myelogenous leukemia. Di Yi Jun Yi Da Хие Хие Bao 24: 1227-9, 1241.

Genetics and Molecular Research 7 (2): 417-423 (2008)

CFUNPEC-RP www.funpecrp.com.br 
Liu Q, Song L, Zhang Y, Wei Y, et al. (2005). The clinical significance of interphase fluorescence in situ hybridization monitoring chimeric status after sex-mismatched allogeneic hematopoietic stem cell transplantation for leukemia. Zhonghua Yi. Xue Yi Chuan Xue Za Zhi 22: 212-215.

Liubimova LS, Savchenko VG, Mendeleeva LP, Kuz'mina LA, et al. (2004). Allogenic bone marrow transplantation in chronic myeloid leukemias. Ter. Arkh. 76: 18-24.

Olavarria E, Ottmann OG, Deininger M, Clark RE, et al. (2003). Response to imatinib in patients who relapse after allogeneic stem cell transplantation for chronic myeloid leukemia. Leukemia 17: 1707-1712.

Petzer AL and Gunsilius E (2003). Hematopoietic stem cells in chronic myeloid leukemia. Arch. Med. Res. 34: 496-506.

Posthuma EF, Marijt EW, Barge RM, van Soest RA, et al. (2004). Alpha-interferon with very-low-dose donor lymphocyte infusion for hematologic or cytogenetic relapse of chronic myeloid leukemia induces rapid and durable complete remissions and is associated with acceptable graft-versus-host disease. Biol. Blood Marrow Transplant. 10: 204-212.

Qian SX, Li JY, Zhang R, Hong M, et al. (2006). Monitoring of bcr/abl fusion gene by interphase-dual-color and dual-fusion fluorescence in situ hybridization in CML after allo-HSCT. Zhongguo Shi Yan. Xue Ye Xue Za Zhi 14: 577-581.

Qin YZ, Li JL, Zhu HH, Ruan GR, et al. (2006). Monitoring bcr-abl mRNA levels by real-time quantitative RT-PCR in chronic myeloid leukemia patients after hematopoietic stem cell transplantation. Zhonghua Xue Ye Xue Za Zhi 27: 511-514.

Simon W, Segel GB and Lichtman MA (2006). Early allogeneic stem cell transplantation for chronic myelogenous leukemia in the imatinib era: a preliminary assessment. Blood Cells Mol. Dis. 37: 116-124.

Soydan E, Civriz S, Beksac M, Koc H, et al. (2005). Imatinib only for molecular relapse is not sufficient to achieve a durable complete chimeric status and molecular remission after allo HCT in CML. Biol. Blood Marrow Transplant. 11: 25 .

Thomas ED and Clift R (1998). Allogeneic transplantation for chronic myelogenous leukemia. In: Hematopoietic cell transplantation (Thomas ED, Blume GK and Forman SJ, eds.). Blackwell-Sciense, Boston, 807-816.

Turkiewicz D, Gorczynska E, Toporski J, Kalwak K, et al. (2003). Monitoring of hematopoietic chimerism after sexmismatched allogeneic stem cell transplantation (alloSCT) by dual-color FISH analysis of X and Y chromosomes. Leuk. Res. 27: 993-998.

Valcarcel D, Martino R, Sureda A, Canals C, et al. (2005). Conventional versus reduced-intensity conditioning regimen for allogeneic stem cell transplantation in patients with hematological malignancies. Eur. J. Haematol. 74: 144-151.

Vendrame-Goloni CB, Varella-Garcia M, Carvalho-Salles AB, Ruiz MA, et al. (2003). Translocation (11;19)(q23;p13.3) associated with a novel $\mathrm{t}(5 ; 16)(\mathrm{q} 13 ; \mathrm{q} 22)$ in a patient with acute myelocytic leukemia. Cancer Genet. Cytogenet. 141: 71-74.

Vinogradova OA, Savchenko VG, Domracheva EV, Liubimova LS, et al. (2002). Molecular cytogenetic monitoring of chimerism and minimal residual disease in patient with chronic myeloid leukemia after allogenic and syngenic bone marrow transplantation. Ter. Arkh. 74: 38-44.

Wickenhauser C, Thiele J, Perez F, Varus E, et al. (2002). Mixed chimerism of the resident macrophage population after allogeneic bone marrow transplantation for chronic myeloid leukemia. Transplantation 73: 104-111.

Yang DL, Han MZ, Feng SZ, Wang M, et al. (2004). Second allogeneic transplant for leukemia relapsed after first allogeneic transplantation. Zhonghua Xue Ye Xue Za Zhi 25: 285-289.

Yokota H, Tsuno NH, Tanaka Y, Fukui T, et al. (2002). Quantification of minimal residual disease in patients with e1a2 BCR-ABL-positive acute lymphoblastic leukemia using a real-time RT-PCR assay. Leukemia 16: 1167-1175. 